\title{
Family Income and Postsecondary Education In Canada
}

\section{LOUIS N. CHRISTOFIDES ${ }^{\dagger}$, JIM CIRELLO ${ }^{\ddagger}, \&$ MICHAEL HOY ${ }^{*}$ †University of Guelph, $\ddagger_{\text {Bell Canada }}$}

\begin{abstract}
We use data from the Surveys of Consumer Finance (1975-1993) to examine how postsecondary education participation rates have evolved over time and how certain variables may affect them. A number of socioeconomic influences are shown to affect participation rates. Beyond these, particularly pronounced trend increases in postsecondary education attendance for children from low-income households have led to a convergence in the participation rates of children from different income groups and a consequent reduction in the regressivity associated with subsidies for postsecondary education. We consider possible reasons for this convergence. Conditioning on a number of other variables, we are particularly interested in the possibility that increases in family real income may have affected the demand for postsecondary education by

\footnotetext{
* Drs. Christofides and Hoy are indebted to the SSHRC for financial support. Much of the work for this paper was done while L.N. Christofides was visiting the University of Cyprus and M. Hoy was visiting G.R.E.Q.A.M., Université d'Aix Marseille and CNRS; they thank them for their hospitality and financial support. The authors are indebted to M. Dooley, R. Finnie, B. Wandschneider and participants at the Canadian Economic Association Meetings at Brock University and at the faculty seminar at the Department of Economics, the University of Cyprus, for helpful discussions and suggestions. Constructive comments were also received from two anonymous referees. The views expressed in this paper are those of the authors and do not necessarily represent those of their institutions.
} 
children from low-income families more than the demand by children from high-income households. We find that, although income does have a statistically significant non-linear influence which can explain much of the cross-sectional difference in attendance at postsecondary institutions, its quantitative effects are not sufficiently strong to account for the convergence over time in participation by children from different family income groups.

\section{RÉSUMÉ}

Avec les informations fournies par les Sondages des finances des consommateurs (1975-1993), on y examine de quelle façon les taux de fréquentation ont évolué au fil des années dans les établissements d'enseignement postsecondaire et de quelle façon certaines variables pourraient les affecter. Il est démontré que plusieurs influences socioéconomiques ont affecté les taux de fréquentation dans les établissements d'enseignement postsecondaire. En plus, une tendance marquée à l'augmentation de l'inscription des enfants de familles à faible revenu a mené à une convergence dans les taux de fréquentation des enfants provenant de divers milieux économiques et ainsi une baisse de la régression associée aux subventions pour l'éducation postsecondaire. On y considère les raisons possibles pour cette convergence. Prenant en considération plusieurs variables, on s'intéresse particulièrement à la possibilité que les augmentations réelles dans les revenus familiaux auraient pu affecter la demande d'éducation postsecondaire pour les enfants de familles à faible revenu davantage que pour ceux de familles à revenu élevé. On démontre que, même si le niveau de revenu exerce une influence non-linéaire statistiquement significative qui peut expliquer en grande partie la différence dans la fréquentation des établissements d'enseignement postsecondaire, les effets quantitatifs ne sont pas suffisamment importants pour expliquer la convergence, au fil des années, des taux de fréquentation dans les établissements d'enseignement postsecondaire des enfants de divers milieux économiques. 


\section{INTRODUCTION}

Accessibility to postsecondary education is an important social issue on both efficiency and equity grounds. The existence of social and/or economic barriers which impede children from lower income families from obtaining a postsecondary education limits their potential productivity and earnings capabilities, hence limiting growth in the economy, and also raises concerns about equality of opportunity and social mobility. Since postsecondary education is heavily subsidized from tax revenues, higher attendance rates from higher income families will have the effect of diminishing the degree of progressivity in the income tax system and possibly even making postsecondary education financing regressive. Highly educated individuals, who are disproportionately represented from high income families, receive larger amounts of subsidized education than those who do not directly partake in its benefits but who also contribute to the funding of education. The result is that these government subsidies disproportionately favour high-income families and their children, who also tend to end up receiving increased future earnings generated by their postsecondary education (see Bar-Or, Burbidge, Magee, \& Robb, 1995; Vaillancourt, 1995).

One purpose of our paper is to examine any trends in the participation rates in postsecondary education for children from families with different income levels in order to determine whether, from a public finance perspective, these subsidies are becoming relatively more or less regressive. Our analysis also sheds some light on the issue of the extent to which postsecondary education in Canada has the potential to increase social mobility and reduce inequality. In particular, we examine the possibly changing role of family income as a factor in these relationships. Since private returns to postsecondary education are substantial, social mobility will be enhanced if participation rates in postsecondary education are increasing more rapidly for children from lower income families. The relationship between current education levels and future earnings in the distribution of income is complex and so our analysis indicates only the potential role of changes in the relationship between family income and postsecondary education attendance in reducing 
inequality and enhancing social mobility. However, there is abundant evidence that there is a strong link between the level of education and a person's income. Thus, if the participation rates in postsecondary education for children from lower income families increases relative to that of children from higher income families, then one can expect, with a high degree of confidence, that we will observe greater social mobility and less inequality of incomes than would otherwise be the case. ${ }^{1}$ To address all of these issues it is important to separate the effects of various economic and non-economic factors which influence whether an individual attends a postsecondary educational institution, and this is what we do here.

Studies for developed and underdeveloped countries generally show that children from higher income families are more likely to obtain a postsecondary education. ${ }^{2}$ Mehmet (1978), who looks at this question using Ontario data for 1974, finds that even though lower income families contribute less towards the funding of postsecondary education due to lower income tax payments, the use of postsecondary education by children of high income families is sufficiently intense that the overall system is regressive. ${ }^{3}$ Besides differing enrolment rates, he shows that among children who do attend postsecondary educational institutions, those from higher income families are more likely to take more costly and higher return programs such as medicine, dentistry and law. The view that subsidized postsecondary education is regressive continues to receive widespread acceptance. In a recent article in his university's magazine, James Downey (1996), President of the University of Waterloo remarks that:

Despite... high participation rates, we have succeeded in attracting too few women and men from the lower socioeconomic classes; university education is still largely a middleand upper-class preserve, subsidized by everyone, even those who do not participate. Thus, both the general economic and social-equity arguments for the very high level of public investment in universities and colleges have been losing force. (p. 13)

In this paper we use Canadian data over the period 1975 to 1993 to investigate whether the force of the Downey criticism may have changed over time. We discover that, although attendance rates for postsecondary 
education continue to be higher for children from higher income families than from lower income families, there has been a strong degree of convergence. From 1975 to 1993 the overall percentage of children in the 18 to 24 year-old cohort attending postsecondary education rose from $33 \%$ to $54 \%$, with a substantially larger increase (18\% to $44 \%$ ) in the participation rates of children from families in the poorest quintile of the income distribution relative to those from the highest quintile $(53 \%$ to $71 \%$ ). Although the participation rate in the highest quintiles has an upper ceiling, which may actually be lower than unity, ${ }^{4}$ there is no necessary reason for the rate in the lower income quintiles to increase over time. In this paper we explore possible reasons why this convergence may have occurred.

One force which may account for this convergence is the growth of real incomes through time. Though quintile family income shares have remained relatively stable over the period 1975-1993, average real incomes within each quintile have risen substantially. If the marginal effect on postsecondary school attendance of an increase in family income is greater for lower income families, then a plausible explanation for the convergence in participation rates between high and low-income families is that generally rising real incomes may have led to a greater increase in attendance for relatively low-income families than for highincome families. We investigate this possibility by considering whether participation rates depend in a non-linear manner on absolute income levels. In assessing the role of income, it is necessary to take into account the possible role of other influences such as parental educational attainment and the broad costs of and returns to postsecondary education on participation rates. Without these forces clearly accounted for, the role of real income cannot be reliably established. (That is, regression equations which omit relevant explanatory variables will measure the role of included variables, such as income, inappropriately.) We conclude that income is an independent and statistically significant determinant of postsecondary education attendance, but not a plausible cause of the observed convergence in relative participation rates. We identify trend increases in postsecondary education attendance which are above and beyond the influence of the explanatory variables that we have been 
able to consider. While these forces are controlled for through time effects, further research is needed in order to better appreciate the mechanisms that shape postsecondary education attendance in Canada.

In the next section, we present trends demonstrating the relative increase in accessibility of postsecondary education for children from low income families and the concomitant reduction in the degree of regressivity in the system. In the third section, we discuss the data and sources used in this study while, in the fourth section, we present an econometric analysis of the role of income and other determinants of postsecondary attendance. We present concluding observations in the final section.

\section{REGRESSIVITY OF GOVERNMENT SUBSIDIES TO POSTSECONDARY EDUCATION}

In Table 1 we present, for each income quintile and for selected years, the proportion of children from the age group 18 to 24 years old who attend postsecondary education - we call this variable PROP. ${ }^{6} \mathrm{~A}$ general increase in the proportion of children attending postsecondary education is evident over this period for all income groups (see also Table 5). Dividing the proportion for the top quintile by the proportion in the bottom quintile for the same year, we see in Table 2 that in 1975 a child from a family in the top quintile of the income distribution was 2.94 times more likely to be enrolled in a postsecondary education program than a child from a family in the bottom quintile. This figure shrank to 1.61 by 1993 . From this relative perspective at least, there has been a reduction in the extent to which government funding for postsecondary education is regressive. A similar trend exists, in Table 3 , for the number of children attending postsecondary programs - we call this variable CAS for Children at School.

Why has this convergence occurred? One plausible explanation is that, under imperfect capital markets, rising absolute incomes have a greater impact on postsecondary education attendance for the poor than for the rich. ${ }^{7}$ We consider the possibility that rising incomes are more important for lower income families by dividing the sample into income 
Table 1

Proportion of Children (PROP) in Postsecondary Education by Quintile

\begin{tabular}{lccccc}
\hline \multicolumn{5}{c}{ Family Income Quintiles } \\
\cline { 2 - 6 } Year & First & Second & Third & Fourth & Fifth \\
\hline 1975 & 0.18 & 0.26 & 0.33 & 0.46 & 0.53 \\
1977 & 0.25 & 0.31 & 0.36 & 0.41 & 0.52 \\
1981 & 0.26 & 0.34 & 0.38 & 0.43 & 0.54 \\
1985 & 0.32 & 0.37 & 0.40 & 0.45 & 0.57 \\
1989 & 0.35 & 0.41 & 0.45 & 0.53 & 0.62 \\
1993 & 0.44 & 0.49 & 0.55 & 0.59 & 0.71
\end{tabular}

Source: Survey of Consumer Finance, various years. A number such as 0.18 for the first quintile in 1975 indicates that in the actual families of that quintile, the variable PROP (i.e., the proportion of children attending postseconary education) is on average equal to 0.18 . See the next section for variable definitions.

Table 2

The Relative Likelihood of Postsecondary Education

\begin{tabular}{lc}
\hline Year & Fifth Quintile Relative to First Quintile \\
\hline 1975 & 2.94 \\
1977 & 2.08 \\
1981 & 2.08 \\
1985 & 1.78 \\
1989 & 1.77 \\
1993 & 1.61
\end{tabular}

Source: Survey of Consumer Finance, various years and Table 1. 
Table 3

\section{Absolute Number of Children (CAS) in Postsecondary Education by Quintile}

\begin{tabular}{lccccc}
\hline \multirow{5}{*}{ Year } & \multicolumn{5}{c}{ Family Income Quintiles } \\
\cline { 2 - 6 } & First & Second & Third & Fourth & Fifth \\
\hline 1975 & 0.25 & 0.34 & 0.45 & 0.58 & 0.70 \\
1977 & 0.34 & 0.44 & 0.48 & 0.55 & 0.70 \\
1981 & 0.34 & 0.44 & 0.52 & 0.61 & 0.74 \\
1985 & 0.40 & 0.46 & 0.53 & 0.58 & 0.75 \\
1989 & 0.43 & 0.52 & 0.56 & 0.69 & 0.80 \\
1993 & 0.53 & 0.63 & 0.71 & 0.79 & 0.91
\end{tabular}

Source: Survey of Consumer Finance, various years. A number such as 0.25 for the first quintile in 1975 indicates that in the actual families of that quintile, the variable CAS(i.e., the absolute number of children in postseconary education) is on average equal to 0.25 . See the next section for variable definitions.

\section{Table 4}

\section{Proportion of Children (PROP) in Postsecondary Education by Income Group (1986 constant dollars)}

\begin{tabular}{lllllll}
\hline Income & \multicolumn{7}{c}{ Year } \\
\cline { 2 - 7 } Range (\$) & 1975 & 1977 & 1981 & 1985 & 1989 & 1993 \\
\hline $0-5,000$ & 0.14 & 0.28 & 0.26 & 0.40 & 0.38 & 0.33 \\
$5,001-10,000$ & 0.19 & 0.20 & 0.20 & 0.25 & 0.28 & 0.47 \\
$10,001-20,000$ & 0.22 & 0.27 & 0.29 & 0.36 & 0.39 & 0.46 \\
$20,001-30,000$ & 0.31 & 0.32 & 0.35 & 0.39 & 0.40 & 0.49 \\
$30,001-40,000$ & 0.44 & 0.36 & 0.40 & 0.39 & 0.43 & 0.54 \\
$40,001-50,000$ & 0.48 & 0.41 & 0.43 & 0.48 & 0.55 & 0.58 \\
$50,001-60,000$ & 0.54 & 0.45 & 0.46 & 0.49 & 0.53 & 0.61 \\
$60,001-70,000$ & 0.51 & 0.55 & 0.49 & 0.57 & 0.62 & 0.73 \\
$70,001-80,000$ & 0.64 & 0.53 & 0.58 & 0.63 & 0.55 & 0.75 \\
$80,001-90,000$ & 0.59 & 0.65 & 0.63 & 0.55 & 0.69 & 0.72 \\
$90,001-100,000$ & 0.65 & 0.60 & 0.73 & 0.75 & 0.72 & 0.75 \\
$100,000+$ & 0.77 & 0.65 & 0.60 & 0.60 & 0.77 & 0.59
\end{tabular}

Source: Survey of Consumer Finance, various years and Table 1. 
categories based on absolute (1986 dollars) income levels, rather than the relative values in the quintiles. Using the variable PROP examined in Tables 1 and 2, Table 4 shows that, regardless of year, the participation rates for the children of low-income families are much lower than those for the children of high-income families. Within each SCF year, as income rises, participation rates increase, albeit at a diminishing rate. Taken together, these effects could mean that the lowest quintile in Table 1, which contains higher absolute real income levels in 1993 than in 1975 , could also entail an increase in the proportion of children in postsecondary education due to rising income which is much larger than that experienced in the highest quintile. If so, that might explain the convergence noted in Table 2. While this is a plausible argument, and one that has not been investigated in the education literature in Canada, Table 4 also indicates that this force may not be the only one at play. Long-term increases in participation rates are evident even while holding real income constant. Indeed, these increases are particularly clear for low income brackets. For instance, between 1975 and 1993 the participation rate increases from 0.22 to 0.46 in the $\$ 10,000-\$ 20,000$ income category while the increase in the $\$ 70,000-\$ 80,000$ income category is from 0.64 to 0.75 . It would appear, therefore, that while the convergence noted in Tables 1 to 3 is consistent with the notion of imperfect capital markets and income-related effects, it may not be solely due to these forces.

In the next two sections, we investigate more fully the relationship between family income and postsecondary education attendance while, at the same time, controlling for a number of other variables that might be expected to influence postsecondary education decisions.

\section{DATA SOURCES AND VARIABLE DEFINITIONS}

The data for this study are drawn from the available Surveys of Consumer Finance (SCF). These include the SCFs for 1975, 1977, 1979, 1981,1982 , and 1984 to 1993 . Although a survey is available for 1983 , it is not used because information on a critical variable, the number of children attending school, is presented in a manner which is not consistent with the fourteen other SCF surveys. ${ }^{8}$ Each SCF tape was used to 
construct the sub-sample of particular interest, namely that of families with children aged between 18 and 24. ${ }^{9}$ (The SCF defines an economic family as a group of individuals living together and related by blood, marriage or adoption.) Since we are interested in the forces that determine attendance at postsecondary institutions, we focus on the number of children attending school on a full-time or part-time basis. The variable Children at School (CAS), is the subject of study of a Poisson count data model. This model is suitable for the study of count variables such as the number of children at school (CAS). (Note that CAS is the variable used in Table 3.) The propensity for postsecondary education involves the variable CAS in relation to the total number of children (Children) in the relevant age group (18 to 24) in the economic family. In exploratory Ordinary Least Squares (OLS) regressions, we study the variable PROP that is the number of children at school relative to the total number of children of the relevant age in the family (CAS/Children). This is the variable used in Tables 1, 2 and 4. In addition, we report a Probit equation which focuses on the probability that a given family unit will have at least one child at school. In this latter specification, the dependent variable $(I)$ takes the value of 1 if a family has at least one child in postsecondary education and is equal to 0 otherwise. All three specifications take into account the influence of the number of children in the family on the dependent variable - i.e., on the variables PROP, CAS and the Probit index. The three approaches (OLS, Poisson regression and Probit) have different strengths and deal with slightly different aspects of the problem at hand. They are complementary and together they serve to produce some confidence about the statistical significance of the variables used to account for the observed patterns of postsecondary education. The statistical appropriateness and properties of these models are considered further in the next section.

As noted in the second section, household income is likely to be an important force in decisions relating to postsecondary education and is, therefore, included as an explanatory variable in all three specifications. The variable Income is the sum of the head's and spouse's income and it, along with its square, are entered in our equations in real terms. As a 
deflator, we use the All Items Consumer Price Index (CPI) for the major cities of Canada's provinces as reported in appendix Table A.1. ${ }^{10}$

Further explanatory variables include the educational attainment of the head of household. (The education attainment of the spouse is highly co-linear with that of the head.) It is likely that heads with more education will encourage their children to also obtain more education. The following dummy variables are used: Grad equals 1 when the head has completed high school and has no further education; it equals 0 otherwise. Some postsecondary equals 1 when the head has some postsecondary education but no certificate, diploma or degree; it equals 0 otherwise. Postsecondary equals 1 when a certificate or diploma has been achieved and equals 0 otherwise. Finally, Degree equals 1 when a university degree has been achieved and equals 0 otherwise. The omitted category is that of incomplete high school and the effect of the head's education in the estimated equations is measured relative to this baseline case.

The proximity to a postsecondary institution is an important element in the overall cost of obtaining further education. ${ }^{.1}$ Therefore, we include as an explanatory variable the dummy variable Urban which equals 1 when the family resides in an urban area and equals 0 otherwise. A further element in the cost of postsecondary education are real tuition fees. It is well-known that tuition fees in Canada are lower than those in elite institutions in the U.S. and that substantial increases in the Canadian fees did not occur until the latter part of the 1990s. However, this is not an argument for ignoring the relevance of tuition fees on postsecondary attendance in the period under study here. Doing so would, in general, bias the coefficient estimates of the included variables and would deprive us of any basis for estimating the possible reduction of attendance in postsecondary education following the recent, substantial, increases in tuition fees. ${ }^{12}$ We construct the real tuition fee variable using nominal tuition fees in Arts programs at each province's largest university and deflating by the CPI in each province's largest city - see Appendix Table A.1. Tuition fees in Arts programs are very similar to the fees for programs in commerce, education, agriculture, science and music at these institutions. The square of this variable was also considered, but was not 
helpful and was, therefore, not included in the equations that follow. In view of the policy significance of this variable and possible future work in this area, we report real tuition fees in the Appendix Table A.2 and nominal tuition fees in Appendix Table A.3. ${ }^{13}$ It is generally the case that real tuition has increased over time in each and every province and it is one of our purposes to see whether and to what extent these increases have discouraged attendance. This is an important consideration given that one of the main aims of the paper is to assess changes in the degree of regressivity associated with government subsidies for postsecondary education. Tuition increases shift the balance from government funding to private funding.

The potential returns to postsecondary education may depend on the state of local labour markets. With that in mind, but also because regional differences in further costs of and tastes for postsecondary education may exist, we also condition on provincial dummy variables which equal 1 if a family resides in a particular province and are equal to 0 otherwise. (Provincial effects are measured relative to B.C. - the omitted category.) The costs and returns to education are likely to vary over time as well as space. The full description of the returns to education and, in turn, the influence of these on postsecondary education attendance are serious issues that cannot be addressed in their full complexity in this study. Indeed, they raise endogeneity issues (that is, the returns to education may depend on the number of individuals with postsecondary education qualifications) whose resolution would considerably complicate the statistical requirements of our present effort. Yet, the problem of time-varying factors which affect the decision to attend postsecondary education cannot be ignored as doing so would bias the estimators for the variables that we are able to include in this study. To deal with these issues in a relatively straightforward manner, we introduce time effects in the pooled sample we study. ${ }^{14}$ These year dummy variables mop up the effect of any omitted variables with a time dimension and help define the role of our other variables more clearly. At the same time, they do not suffer from possible simultaneity. Given that we condition on a variety of other variables, including income, it is likely that any 
remaining pattern of estimated time effects will reflect long-term trends in the expected net returns to education.

Table 5 presents some sample statistics for each SCF year. Columns 1 and 2 report the size of the total and selected samples in each SCF. As can be seen, the smallest and largest selected samples consist of 3,491 and 5,550 observations in the 1975 and 1982 SCFs respectively. Columns 4, 5 and 6 report the mean values of the variables CAS, Children and PROP. The mean values of CAS and PROP increase over time, while that of Children decreases. Column 3 shows the growth in real income that has occurred over time. It is reasonable to suppose that, as real income rises, liquidity constraints and capital market imperfections weaken and the demand for postsecondary education increases. One important issue that we wish to address is whether the evident increase in postsecondary education is a reflection of a positive income effect, or whether there is a long-term increase over and above the real income effect. The latter situation might arise because of an increase through time in the net returns to education, changes in demographic fundamentals and/or taste changes. These forces should be captured by the time effects included in the pooled sample or by the constant terms in the equations for the separate SCFs. By incorporating squared income as an explanatory variable we can also determine whether at least part of the convergence in postsecondary attendance rates between relatively high and relatively low income families is due to the generally rising absolute incomes across quintiles.

\section{ECONOMETRIC ANALYSIS}

We begin with an exploratory OLS regression of PROP (proportion of children within a family out of the relevant age group who attend some postsecondary educational program) on Income, the Square of Income, time effects, and the other explanatory variables discussed above. This econometric specification does not lend itself to standard hypothesis tests because of the obvious non-normality of the error term and PROP. Nevertheless, the estimated effects are suggestive. The results, which are not reported in detail here, indicate expected patterns 
Table 5

Basic Descriptive Statistics

\begin{tabular}{|c|c|c|c|c|c|c|}
\hline \multirow[b]{2}{*}{ Year } & \multicolumn{2}{|c|}{ Number of Observations } & \multicolumn{4}{|c|}{ Mean Values } \\
\hline & Total & Sub-sample & Real Income & CAS & Children & PROP \\
\hline 1975 & 26,569 & 3,491 & $34,891.14$ & 0.4652 & 1.3191 & 0.3529 \\
\hline 1977 & 39,782 & 4,700 & $36,592.22$ & 0.5054 & 1.3673 & 0.3708 \\
\hline 1979 & 37,440 & 5,180 & $36,314.27$ & 0.4649 & 1.3518 & 0.3391 \\
\hline 1981 & 37,866 & 5,396 & $37,031.58$ & 0.5307 & 1.3638 & 0.3889 \\
\hline 1982 & 37,765 & 5,550 & $36,918.18$ & 0.5503 & 1.3766 & 0.4048 \\
\hline 1984 & 36,413 & 5,013 & $34,914.83$ & 0.5387 & 1.3363 & 0.4063 \\
\hline 1985 & 36,389 & 4,768 & $35,473.43$ & 0.5436 & 1.2836 & 0.4233 \\
\hline 1986 & 32,822 & 4,103 & $37,185.50$ & 0.5623 & 1.2713 & 0.4389 \\
\hline 1987 & 43,710 & 5,428 & $37,688.32$ & 0.5990 & 1.2826 & 0.4643 \\
\hline 1988 & 38,027 & 4,478 & $38,643.81$ & 0.6053 & 1.2737 & 0.4773 \\
\hline 1989 & 41,406 & 4,775 & $39,731.90$ & 0.6019 & 1.2597 & 0.4741 \\
\hline 1990 & 45,580 & 5,231 & $40,182.37$ & 0.6570 & 1.2859 & 0.5144 \\
\hline 1991 & 42,804 & 4,801 & $39,514.92$ & 0.6856 & 1.2713 & 0.5354 \\
\hline 1992 & 40,007 & 4,319 & $39,212.27$ & 0.7297 & 1.2725 & 0.5679 \\
\hline 1993 & 39,489 & 4,395 & 39.767 .93 & 0.7102 & 1.2760 & 0.5530 \\
\hline
\end{tabular}

Source: Survey of Consumer Finance, various years. The variables PROP and CAS are defined in Tables 1 and 3 respectively. The variable Children is the total number of children ages 18-24 in the family. A number such as 1.3191 represents the average number of such children in the families of our sample in 1975. For further details, see the third section. 
of behaviour. (OLS equations were estimated with TSP4.2b.) PROP depends on Income and Income squared with coefficients (t-statistics in brackets) of $0.42926 \mathrm{E}-5(24.35)$ and $-0.15942 \mathrm{E}-10(-10.73)$. The income effect is positive for most levels of income, but because of the negative coefficient on the income squared term, it diminishes as income rises. ${ }^{15}$ The implications of this particular pattern of income effects for the convergence in participation rates, noted in the second section, are not obvious without a further quantitative assessment. A simple calculation involves evaluating the change in PROP which occurs between 1975 and 1993 for selected quintiles due solely to changes in family incomes between those time periods. In 1975, the lowest quintile average real income was $\$ 8,336$ and it grew to $\$ 11,101$ by 1993 , increasing PROP by about 0.011 . The highest quintile average real income increased from $\$ 66,403$ in 1975 to $\$ 74,558$ in 1993 , increasing PROP by about 0.016 . Such income changes have minor effects on PROP and would actually increase the proportion of children attending school more for the high-income than for the low-income group. These calculations suggest, therefore, that while the qualitative income effects are consistent with convergence, the quantitative effects of income are essentially negligible and cannot account for the effects noted in Table $1 .^{16}$

The Head's educational achievement is associated positively with PROP: A university degree, the educational variable with the highest effect relative to the omitted class, increases PROP by 0.270 (41.68). PROP is 0.042 (10.95) higher for urban families than rural ones. The real tuition variable is significant at the $5 \%$ level in a two-sided test and has a coefficient of $-0.321 \mathrm{E}-4(-2.30)$. The variable Children has a coefficient of $0.747 \mathrm{E}-2(0.58)$, with Children Squared carrying a coefficient $-0.465 \mathrm{E}-2(-1.39)$ and neither variable is useful in this exploratory regression. Finally, the coefficients on the provincial dummies range, relative to British Columbia, from $-0.010(-1.19)$ in Alberta to 0.110 (9.67) in Prince Edward Island.

The time effects in the OLS equation increase more or less monotonically both in size and significance from $0.005(0.53)$ in 1977 to 0.159 (14.59) in 1993. (The 1977 intercept is not significantly different from that for 1975, the base year.) Thus, an increase through time in PROP 
across all income groups is suggested. This conclusion also holds in separate OLS regressions for each SCF survey year. Here, the intercept of the estimated equation for each SCF survey year increases over time from 0.075 (1.67) in the 1977 sample to 0.161 (2.29) in 1993.

Conceivably, different time effects for different quintile groups might be supported by the data, a suggestion that would be consistent with the raw data in Table 1. With such effects in mind, the pooled OLS regression was re-estimated, allowing for interactions between year and quintile effects. We treat all base year (1975) quintiles as having the same mean value of PROP once explanatory variables are taken into account. Thereafter, different quintiles are allowed to have a different coefficient both across quintiles and SCF years. Until the 1984 SCF, there is no consistent pattern of quintile/time effects and the coefficients on the quintile/time effects are, in general, not significantly different from zero. Thus, in Table 1, the increases in PROP from the low to the high quintiles may be the result of differences in the average values of explanatory variables in the different quintiles. In addition, until 1984, the differences across years in the value of PROP for given quintiles are not significant. However, for 1984 and 1985 the first quintiles have coefficients ( $t$ ratios) equal to 0.063 (3.41) and 0.086 (4.61) respectively, while the second quintiles have coefficients ( $t$ ratios) equal to 0.046 (2.71) and 0.070 (4.00), respectively. Thus, after 1983 and relative to the base year, the lowest two quintiles begin to display higher values of PROP with the greatest effect occurring in the lowest quintile. From 1986 onwards, all quintiles show consistent increases in PROP with the highest effects occurring in the lowest quintiles. By 1993, for example, the five quintiles have coefficients ( $\mathrm{t}$ ratios) equal to 0.168 (8.63), 0.194 (10.65), $0.150(8.66), 0.137(7.59)$ and 0.154 (7.53). These effects are reasonably representative of the intermediate years as well. These results suggest that there is indeed a tendency for PROP to increase over time and that this increase is larger for lower quintiles. It should be noted, however, that the quintile effects for each SCF year are often not significantly different from each other so that a simple year effect with no quintile interactions is often sufficient. 
Other explanatory variables in this OLS equation have coefficients ( $t$ ratios) which are very similar to those in the simpler specification which just has year effects with no quintile interactions.

The OLS results are based on the most widely used method of assessing the relation between a variable such as PROP and possible explanatory variables and constitute a first pass at the problem. However, they suffer from permitting the predicted values of the dependent variable to lie outside the 0 to 1 interval characterizing PROP and standard hypothesis tests assume that the additive error term is normally distributed. This last assumption implies that values for PROP such as plus and minus infinity are possible. For these reasons it is necessary to check that the variables used in the OLS approach continue to be important in statistically better defined specifications. It would be disturbing, for instance, if income and income squared were not significant variables in alternative specifications. In the alternative specifications considered below, PROP is no longer the dependent variable. Instead, we use (1) the Poisson model for count data which explains integers such as the number of children in postsecondary education (CAS) and (2) the Probit model which describes the probability of having at least one child in postsecondary education (see Greene, 2000). The former seeks to explain the actual number of children at university using:

$$
\operatorname{Prob}\left(C A S=c a s_{n}\right)=e^{\left.-\lambda_{i} \lambda_{i} c a s_{n}\right) / \operatorname{cas}_{n} ! \quad c a s_{n}=0,1,2 \ldots}
$$

where the subscripts $n$ and $i$ index count outcomes and observations respectively and $\lambda_{i}$ is specified as:

$$
\ln \lambda_{i}=\beta^{\prime} X_{i}
$$

The vector $\mathrm{X}_{i}$ contains the explanatory variables described above for the ith observation and the vector $\beta$ the constant coefficients. The marginal effects of changes in variables on the conditional expectation of CAS are given by:

$$
\partial E\left(C A S \mid \mathrm{X}_{i}\right) / \partial \mathrm{X}_{i}=\partial\left(\lambda_{i}\right) / \partial \mathrm{X}_{i}=e^{\beta} \mathrm{X}_{i} \beta
$$


and are analogous to the vector $\beta$ in the OLS context. The Probit model concerns itself with the latent variable $I^{*}$ which determines whether at least one child should attend postsecondary education:

$$
I_{i}^{*}=\gamma^{\prime} \mathrm{X}_{i}+\varepsilon_{i}
$$

where $i$ indexes the $i$ th observation, $\varepsilon_{i}$ is a standard normal variable, the vector $X$ contains the values for the $i$ th observation of the explanatory variables discussed earlier and $\gamma$ is a vector of constant parameters. What we do observe is the variable $I$, that is, whether at least one child did attend postsecondary education and we assume that:

$$
\begin{array}{ll}
I=1 & \text { if } I^{*}>0 \\
I=0 & \text { if } I^{*} \leq 0
\end{array}
$$

The conditional expectation of $I^{*}$ is given by $\mathrm{F}\left(\gamma^{\prime} \mathrm{X}\right)$ and the marginal effects by $f\left(\gamma^{\prime} X\right) \gamma$, where $F$ is the cumulative standard normal and $f$ is the standard normal density function.

Columns 1-3, Table 6, report estimates of the coefficients in the Poisson model, the implied t-statistics and marginal effects, respectively. Column 3 is obtained from column 1 by multiplying by $\lambda=0.4766$, where $\lambda$ has been evaluated at the mean values of $X_{i}$. Columns $4-6$ of Table 6 report similar information for the Probit model. ${ }^{17}$ Marginal effects are presented only for the continuous variables in Table 6.

The results in this table are qualitatively similar to the OLS results reported above. Additional children first increase and, beyond a certain number, decrease the variable CAS and the probability of having at least one child in postsecondary schooling. Residing in urban areas is associated with increases in both CAS and the probability of having at least one child in postsecondary schooling. Higher educational attainment for the family head increases CAS as well as the probability of having at least one child in postsecondary schooling, this effect being most pronounced when the head holds a university degree. The real tuition fee variable, which was only marginally useful in the OLS results, has no significant effect on CAS and is only significant at the $5 \%$ level in the Probit equation. Significant differences between other provinces and British Columbia are present in both specifications (see Table 6). 
However, it is the effects of Income, Income Squared and Time that are of particular interest. Real income continues to be a significant nonlinear influence on both CAS and the probability of having at least one child in postsecondary education. In the Poisson model, real income increases CAS until real income equals $\$ 115,582$ while, in the Probit model, the probability of having at least one child in school rises until real income equals $\$ 126,503$ which, in both cases, accounts for virtually all observed income levels. The year effects in successive SCF surveys increase in both the Poisson and Probit specifications, indicating growth over time in attendance at postsecondary institutions.

It is instructive to use the estimates in these alternative approaches to see whether the rise in real income over time can explain the convergence of interest in postsecondary education attendance across quintiles. In the probit estimates, for instance, the 1975 probability of having at least one child in school is 0.295 for the first and 0.496 for the fifth quintile respectively. ${ }^{18}$ By 1993 these probabilities are 0.308 and 0.516 respectively if the time effect is ignored. That is, the growth in income alone cannot account for a much higher probability of at least one child at school for first (the lowest) quintile families in 1993 relative to 1975. Once the 1993 time effect $(0.45$ in column 4, Table 6$)$ is taken into account, these probabilities become 0.48 and 0.688 respectively and the considerably heightened interest in postsecondary education is captured by the time dummy.

In light of the current policy concern about the possible effects of increases in tuition fees on university attendance, the weak performance of the variable Tuition may come as a surprise. It must be remembered, however, that given the strong time element in this study it is real tuition fees that should be of interest and, as Table A.2 in the appendix shows, these were constant or even declining in many provinces until 1991. In 1991 nominal tuition fees in Quebec were increased for the first time in our sample and by 1993 real tuition fees increase in all provinces above their 1991 levels. It is conceivable that these increases in the cost of education are not given a chance to appear in the equations of Table 6 because the provincial and time effects mop up most of the information in the variable Tuition. In order to explore this possibility we conduct 


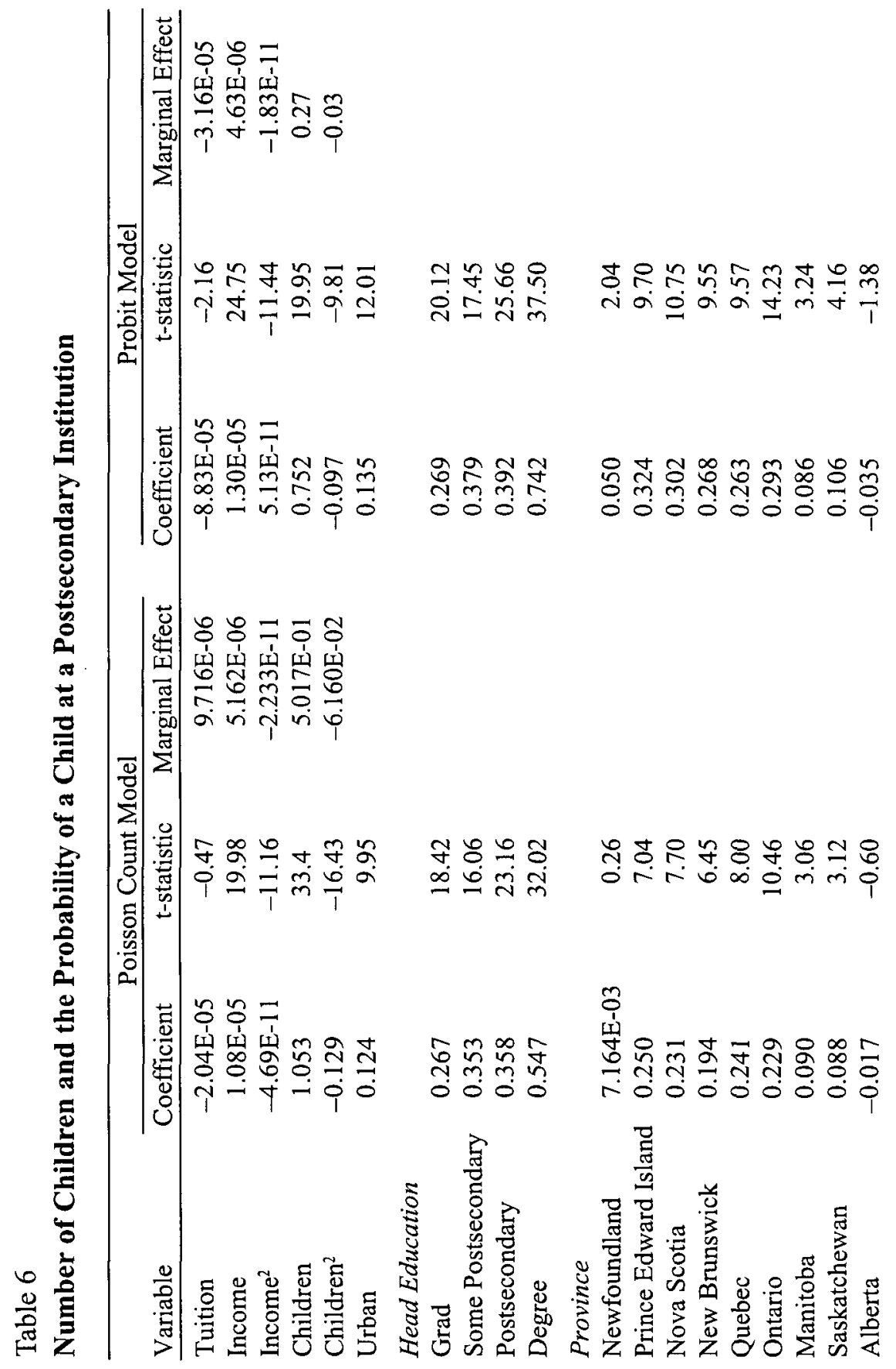




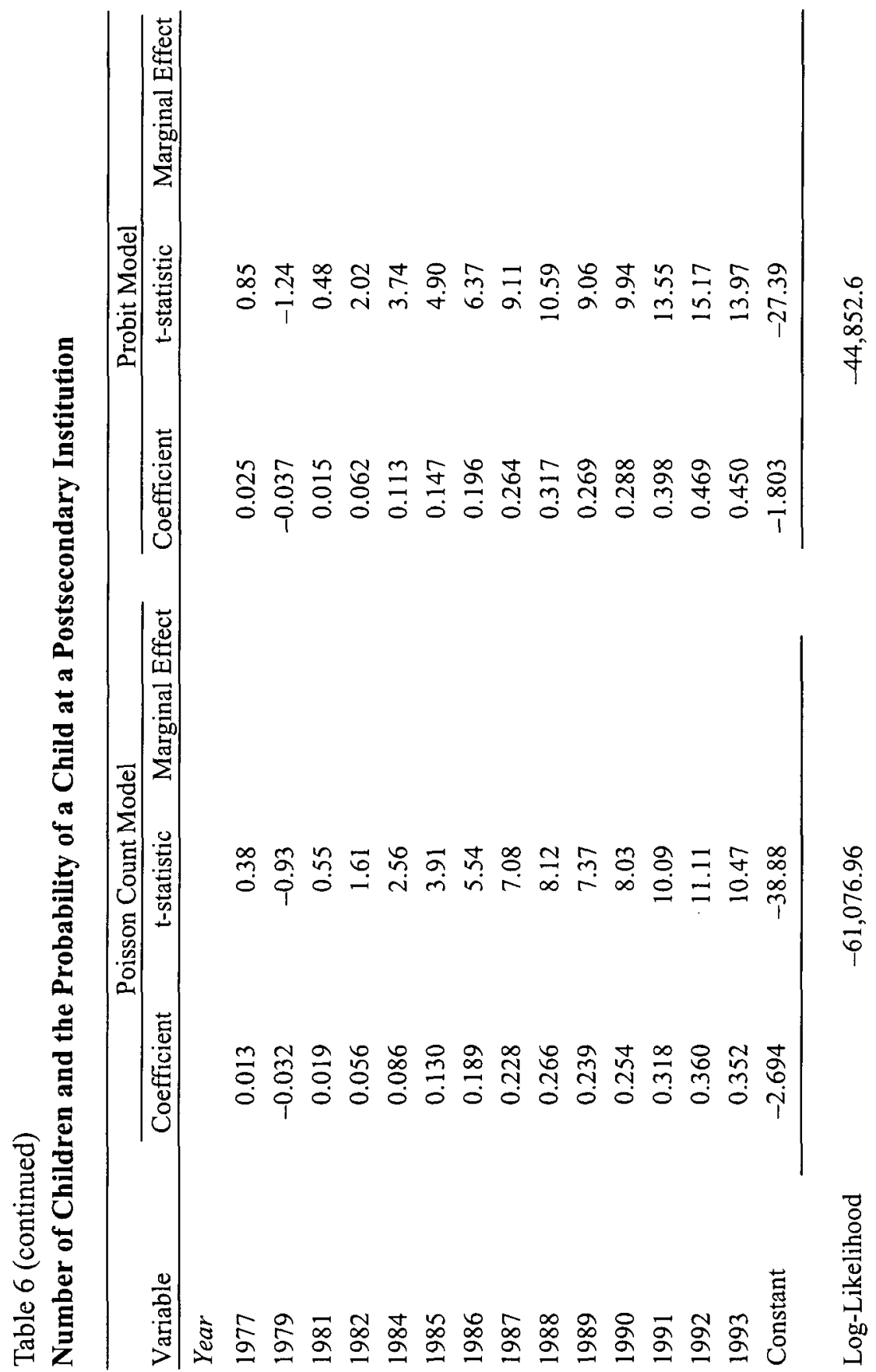


two sensitivity analyses. To begin with, we respecify the equations of Table 6 by removing the time effects and including a time trend (1975 observations are coded as $1 \mathrm{~s}, 1976$ as $2 \mathrm{~s}$, and so on) and time trend squared. If Tuition has a role to play it now has a better chance to fulfill it and, of course, we continue to have an interest in the role of long-term trends. In the Count model, Tuition has a coefficient (t statistic) of $0.36 \mathrm{E}-03$ (12.95); the counter-intuitive positive sign suggests that this variable may be picking up some of the long-term trends in the number of children in postsecondary education. In the Probit equation the coefficient ( $t$ statistic) on Tuition is -0.61E-04 (-1.60) and it is not as welldefined as its counterpart in Table 6. Both specifications produce strong trend effects: In the Count equation the results for trend and trendsquared are 0.0179 (7.98) and $-0.0005(-5.57)$ respectively; in the Probit model they are $0.0022(0.45)$ and $0.0013(5.19)$ respectively. Thus, Tuition does not appear to have a useful role, while the time trend variables continue to be important.

It is possible that the sensitivity analysis above does not go far enough in the sense that it still allows much of the provincial variation in Tuition to be captured by the provincial dummy variables. Separate provincial equations with a trend and trend-squared term offer another way to evaluate the impact of Tuition. At the same time this extension deals with an issue which was noted in footnote 13 , that is, the provincial CPI information allows for no cross-sectional variation for the base year and hence does not provide adequate cross-sectional deflation of nominal variables, including Income and Income Squared (denoted as Income $^{2}$ in the tables). Separate provincial equations deal with this concern as well as the appropriate role for tuition. Accordingly, we re-estimate our equations using provincial sub-samples. In the interests of brevity, we do not report these results in detail. It is noteworthy that Tuition never has the anticipated negative and significant coefficient; indeed, in all Count equations and in the Probit equations for Newfoundland, Prince Edward Island and British Columbia it has a significant, positive, coefficient which, in all likelihood, proxies time effects. The trend and trend-squared variables continue to be important 
except in Prairie provinces where they are not significant in either specification. All other variables continue to perform as indicated above.

To check for the possibility that the variable Tuition does have an effect on postsecondary attendance for low income families, but that this effect is essentially swamped by using the sample based on all families, regardless of income level, we ran the same econometric models as in Table 6 (and OLS as well) for the subsamples defined by the poorest $20 \%$ of families and also for the poorest $40 \%$ of families of the entire sample. ${ }^{19}$ The result was that the variable Tuition continues not to be statistically significant in explaining the dependent variable. Further work using as yet unavailable data for the high-tuition period of the late 1990s would be desirable.

\section{CONCLUSION}

Using econometric analysis based on Survey Consumer Finance data from 1975 to 1993 we have been able to isolate some of the important socio-economic variables which have affected the pattern of attendance at postsecondary educational institutions in Canada over this time period. Parents' income and education level are important independent explanatory variables, as expected. Proximity to a postsecondary institution, as captured by our Urban dummy variable, is also a factor. Provincial dummies are significant as well and reflect regional differences in interest for postsecondary education which are not explained by differences in the other socio-economic variables that have been included. Surprisingly, the level of tuition fees does not turn out to be a relevant factor. Although this may be due to the fact that variation in real tuition fees over this time period was limited, all efforts to allow the variable Tuition to express some effect on postsecondary attendance failed. Despite the inclusion of all of the above-mentioned socioeconomic and regional variables, a persistent and increasing trend in participation in postsecondary education is captured by time dummies included in our econometric equations. Thus, we have demonstrated that, although differentials in family incomes can explain a substantial degree of observed differences in attendance at postsecondary institutions in 
any given year, trends in income levels over time do not explain the relative convergence over time of attendance at postsecondary institutions across quintile groups. ${ }^{20}$

These results shed light on a number of important issues concerning equity and efficiency in the financing of postsecondary education. It is clear that, whatever the reason, the time period 1975 to 1993 has seen a larger increase in postsecondary education for individuals from relatively lower income families. Although individuals from higher income families are still more likely to attend postsecondary education, the extent to which the benefits of government subsidies for postsecondary education are enjoyed disproportionately by higher income individuals and families has been reduced and so the regressive impact of government subsidization of postsecondary education has fallen over this period. Our results suggest that, although the expected positive effect of increasing family income on postsecondary education participation is stronger at lower income levels, this property in conjunction with overall increasing family income over this period is not strong enough to explain the higher rate of growth of postsecondary participation rates of children from lower income families. Alternatively, long-term trends in postsecondary education have been very important and relatively more important for low income families in explaining increasing rates of participation in postsecondary education. Income, however, continues to exert a strong influence on participation rates for any given year. This suggests that imperfect capital markets may continue to play a role in determining the decision to attend postsecondary education. Finally, to the extent that there has been significant convergence in participation rates in postsecondary education between income classes, which is independent of trends in income levels, there is reason to believe that trends in postsecondary education attendance will exert a positive influence on social mobility and equality of incomes in the future.

To understand more fully the reasons for the trends suggested by the results of this paper, continued work will be required. 


\section{Notes}

1 Other economic factors may be at work to increase inequality over time. However, any narrowing of the differences in postsecondary education levels between children from families of different income levels should at least limit any increases in inequality that would otherwise be observed.

2 Studies which support this claim include Hansen \& Weisbrod (1969), Radner \& Miller (1970), Peltzman (1973), Jackson \& Weathersby (1975) and Bishop (1977). Psacharopoulos (1986) documents studies for several developing countries. For Canada, see Mehmet (1978) and Meng \& Sentance (1982). Also, see Anisef, et al. (1985) for a summary of other Canadian studies which show consistently that individuals from families of higher socio-economic status are more likely to enter postsecondary educations. For a wide-ranging set of references on education in Canada, see Guppy \& Davies (1998).

3 He shows that the lowest income class (less than $\$ 2000$ income in 1970 dollars) receives benefits from postsecondary education which exceed their tax contributions. This result occurs since this income group contributes almost nothing to tax revenues. However, the next three income groups (\$2000 to $\$ 10,000$ ) all contribute more than they receive in benefits from the education system while the opposite holds for those earning in excess of $\$ 10,000$.

4 The SCF category of 18-24 year olds will inevitably include individuals who have no interest in further education as well as those who have already graduated from university but are still captured in this category.

5 Osberg (1996), for example, shows that, except for the effect of recessions, there has been little change in inequality in Canada over the period 1975 to 1994. See also Wolfson (1986).

6 Data from the 1975-1993 Surveys of Consumer Finance (selected years as available) are used in this study because this information is available for many more years than is the case with data from other sources such as the census. In accordance with standard procedures, we use the sampling weights provided by the Surveys in determining the means of variables. Not to do so would generate biased estimates due to the fact that the surveys do not sample households of different types with equal probability. The age group 18-24 years of age represents the age group which has traditionally been most interested in postsecondary education - see the third section for a more detailed discussion of the data used in this study. Guppy and Davies (1998, pp. 90-92) show that, over this period, the participation rate for females has increased more dramati- 
cally than that for males, suggesting that separate analyses by gender would be desirable. Unfortunately, the SCF data do not identify the gender of the children in the 18-24 year bracket.

7 Although students can be expected to earn substantially higher incomes as a result of their education, this "human capital" is embodied in the person and cannot be used as collateral for a loan as is the case for financial and physical assets. This makes it difficult for students to borrow funds from private lenders. This constraint is especially binding for children from low income families who have greater difficulty directly providing funds for their children or helping them secure loans from the private sector.

8 For 1983, this data is provided for only two categories (1) one child and (2) two or more within the single age grouping of 18 to 24 , while other SCFs report the actual number of children in school. It is also the case that restrictions such as for the 1983 data set apply to the 1984 and 1985 data sets, but the age groupings are split into two, 18 to 21 and 22 to 24 , and so these restrictions are not likely to be binding in many cases.

9 We note that this SCF group may include some individuals who are still at high school and may exclude some individuals who are engaged in postgraduate studies. It may also exclude some young adults who have set up households on their own. In order to ascertain the magnitude of this problem, we examined the Individual SCF files, isolating all 18-24 year olds who are in fulltime college or university attendance. In 1993 for example, only $4.83 \%$ of the 18 year olds in this group described themselves as household heads. Naturally, this figure increases as age increases and by the age of twenty-two, this figure is $17.52 \%$. We assume that household formation is dependent on whether parents are still alive, whether they live together in a single household, and other factors which we treat as exogenous. Subject to these caveats, we refer to the schooling undertaken by the 18-24 year olds in the families of our sample as postsecondary education. It should be noted that, as Mitchell (1994) has shown, females are likely to leave the family nest earlier than males. Unfortunately, we are not able to take gender effects into account using the SCF data.

10 Note that these indices set $1986=100$. See Statistics Canada, The Consumer Price Index (62-001).

11 Card (1995) examines the relevance of this variable for estimates of the return to education. 
12 We note, however, that the variance of real tuition fees may have been too small to allow us to reliably estimate the relevance of this variable. This is a matter that we cannot prejudge. We return to this issue below.

13 Because, as indicated in Appendix Table A.1, the CPI in 1986 $=100$ in all provinces, the reader is cautioned against comparisons of real tuition across provinces. We return to this issue below.

14 Effects are measured relative to 1975 - the omitted category. For computational convenience and ease of reporting and interpretation, we report in detail only pooled results where the intercept terms are assumed to differ across province and the fourteen SCFs but include no interactions between time and province-specific effects. We do, however, also discuss results based on separate equations in exploratory OLS equations. As noted below, these suggest similar conclusions as the pooled data with time effects.

15 The quadratic term results in a negative derivative for levels of real income beyond $\$ 134,632$. It should be noted, however, that family income (in constant 1986 dollars) exceeds $\$ 100,000$ for only $1.5 \%$ of the families in the sample so that the income effect is positive for most families in the sample.

16 This does not mean that income is unimportant. The difference in average incomes between the highest and lowest quintiles explains a good deal of the cross-sectional variation in postsecondary education attendance. For instance, this difference is 0.18 for 1975 and 0.17 for 1993 . The effect of 0.18 for 1975 is evaluated as $(0.42926 \mathrm{E}-5$ times the 1975 fifth quintile average income of $\$ 66,403$ plus $0.15942 \mathrm{E}-10$ times $\$ 66,403$ squared) minus (0.42926E-5 times the 1975 first quintile average income of $\$ 8,336$ plus $-0.15942 \mathrm{E}-10$ times $\$ 8,336$ squared). A similar calculation explains the figure for 1993 keeping in mind that the first quintile average real income is by then $\$ 11,101$ while that for the fifth quintile is $\$ 74,558$.

17 The Poisson count model was estimated with LIMDEP6.0 while the Probit model was estimated using TSP4.2b.

18 To calculate these probabilities we multiply the estimated coefficients in the probit column of Table 6 by the variable means and add these up. We then evaluate the income and income squared terms times their respective coefficients for each quintile. The overall sum of all these terms is the value of the argument in the probit approach. The estimated probability is given by the value of the cumulative standard normal distribution at the value of the argument.

19 The cut-off income level (in 1986 dollars) for the poorest $20 \%$ in the entire sample is $\$ 15,575$ and for the poorest $40 \%$ is $\$ 26,333$. 
20 It is conceivable that, by including the time effects, the hypothesis that higher absolute levels of real income can explain the increased interest in postsecondary education has been subjected to far too stringent a test. Further work in this area, which unbundles the effects captured by the time dummies into the influence of relevant variables such as exogenous measures of the returns to education, would be very desirable.

\section{References}

Anisef, P., Bertrand, M.-A., Hortian, U., \& James, C.E. (1985). Accessibility to postsecondary education in Canada: A review of the literature. Toronto, ON: Ministry of Education.

Bar-Or, Y., Burbidge, J., Magee, L., \& Robb, A.L. (1995). The wage premium to a university education in Canada, 1971-1991. Journal of Labor Economics, 13(4), 762-794.

Bishop, J. (1977). The effect of public policies on the demand for higher education. Journal of Human Resources, 12(3), 285-307.

Card, D. (1995). Using geographic variation in college proximity to estimate the return to schooling. In L.N. Christofides, E.K. Grant, \& R. Swidinsky (Eds.), Aspects of labour market behaviour: Essays in honour of John Vanderkamp (pp. 201-221). Toronto, ON: University of Toronto Press.

Downey, J. (1996). Turning adventure into advantage. University of Waterloo Magazine, (Winter), 12-14.

Greene, W.H. (2000). Econometric analysis, 4th ed. Englewood Cliffs, NJ: Prentice Hall.

Guppy, N., \& Davies, S. (1998). Education in Canada: Recent trends and future challenges. Ottawa, ON: Statistics Canada.

Hansen, W.L., \& Weisbrod, B.A. (1969). The distribution of costs and direct benefits of public higher education: The case of California. Journal of Human Resources, 4(2), 176-191.

Jackson, G.A., \& Weathersby, G.B. (1975). Individual demand for higher education: A review and analysis of recent empirical studies. Journal of Higher Education, 46(6), 623-652.

Meng, R., \& Sentance, J. (1982). Canadian universities: Who benefits and who pays? The Canadian Journal of Higher Education, 12(3), 45-58. 
Mehmet, O. (1978). Who benefits from the Ontario university system? Toronto, ON: Ontario Economic Council.

Mitchell, B. (1994). Family structure and leaving the nest: A social resource perspective. Sociological Perspectives, 37(4), 651-671.

Osberg, L. (1996). Economic growth, income distribution, and economic welfare in Canada, 1975-1994. Halifax, NS: Dalhousie University.

Peltzman, S. (1973). The effect of government subsidies-in-kind on private expenditures: The case of higher education. The Journal of Political Economy, 81(1), 1-27.

Psacharopoulos, G. (1986). Financing education in developing countries. Washington, DC: World Bank.

Radner, R., \& Miller, L. (1970). Demand and supply in U.S. higher education: A progress report. American Economic Review, 60(2), 326-334.

Vaillancourt, F. (1985). The private and total returns to education in Canada, 1985. Canadian Journal of Economics, 28(3), 532-554.

Wolfson, M. (1986). Stasis amid change: Income inequality in Canada, 1965-1983. The Review of Income and Wealth, 32(4), 337-369. 


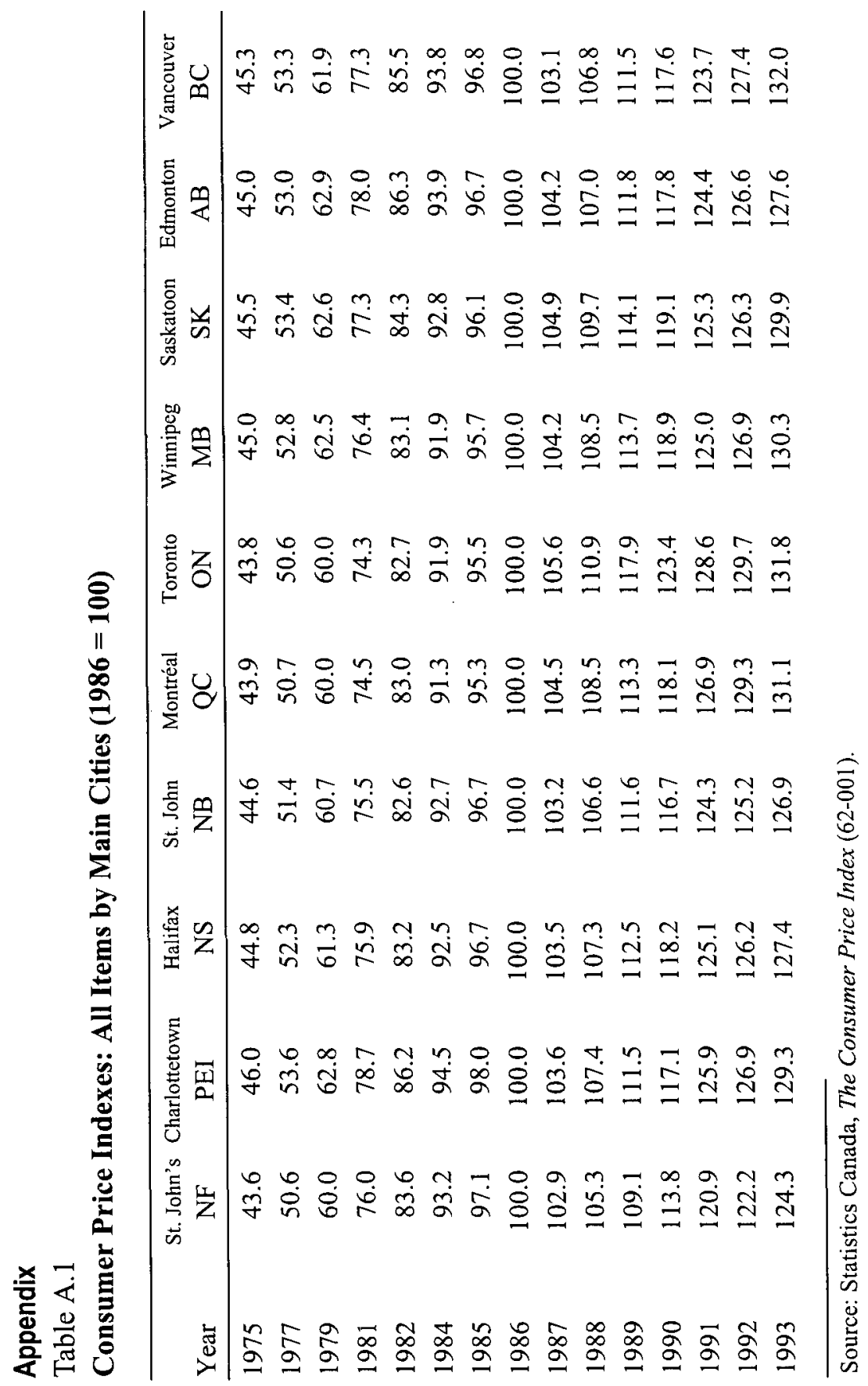


Table A.2

Real Tuition Fees for Full-time Students at Canadian Universities

\begin{tabular}{|c|c|c|c|c|c|c|c|c|c|c|}
\hline Year & $\begin{array}{c}\text { Memorial } \\
\text { NF }\end{array}$ & $\begin{array}{c}\mathrm{U} \text { of } \mathrm{PEI} \\
\text { PEI }\end{array}$ & $\begin{array}{c}\text { Dalhousie } \\
\text { NS }\end{array}$ & $\begin{array}{c}\mathrm{U} \text { of } \mathrm{NB} \\
\mathrm{NB}\end{array}$ & $\begin{array}{c}\text { U of Québec } \\
\text { QC }\end{array}$ & $\begin{array}{c}\mathrm{U} \text { of } \mathrm{T} \\
\mathrm{ON}\end{array}$ & $\begin{array}{c}\text { U of Man. } \\
\text { MB }\end{array}$ & $\begin{array}{c}\text { U of Sask. } \\
\text { SK }\end{array}$ & $\begin{array}{c}\text { U of Alberta } \\
\text { AB }\end{array}$ & $\begin{array}{l}\text { UBC } \\
\text { BC }\end{array}$ \\
\hline 1975 & 1147 & 1304 & 1451 & 1303 & 1144 & 1276 & 944 & 1011 & 889 & 945 \\
\hline 1977 & 988 & 1231 & 1243 & 1440 & 986 & 1294 & 852 & 974 & 943 & 803 \\
\hline 1979 & 1050 & 1194 & 1248 & 1219 & 835 & 1133 & 864 & 998 & 874 & 866 \\
\hline 1981 & 829 & 1099 & 1206 & 1126 & 672 & 1124 & 805 & 893 & 776 & 763 \\
\hline 1982 & 825 & 1102 & 1210 & 1132 & 600 & 1106 & 806 & 819 & 702 & 760 \\
\hline 1984 & 957 & 1270 & 1427 & 1348 & 548 & 1198 & 767 & 938 & 820 & 940 \\
\hline 1985 & 964 & 1296 & 1458 & 1370 & 525 & 1210 & 811 & 978 & 856 & 1193 \\
\hline 1986 & 1006 & 1350 & 1466 & 1400 & 500 & 1215 & 822 & 1015 & 852 & 1275 \\
\hline 1987 & 1026 & 1429 & 1473 & 1526 & 478 & 1197 & 852 & 1025 & 843 & 1280 \\
\hline 1988 & 1052 & 1453 & 1477 & 1571 & 461 & 1217 & 899 & 1080 & 903 & 1292 \\
\hline 1989 & 1067 & 1471 & 1467 & 1591 & 441 & 1196 & 1064 & 1122 & 890 & 1305 \\
\hline 1990 & 1125 & 1469 & 1447 & 1607 & 423 & 1229 & 1120 & 1129 & 907 & 1365 \\
\hline 1991 & 1112 & 1461 & 1415 & 1589 & 670 & 1274 & 1174 & 1180 & 988 & 1358 \\
\hline 1992 & 1264 & 1671 & 1739 & 1677 & 1021 & 1365 & 1384 & 1449 & 1116 & 1460 \\
\hline 1993 & 1368 & 1763 & 1896 & 1852 & 1080 & 1437 & 1577 & 1912 & 1262 & 1409 \\
\hline
\end{tabular}




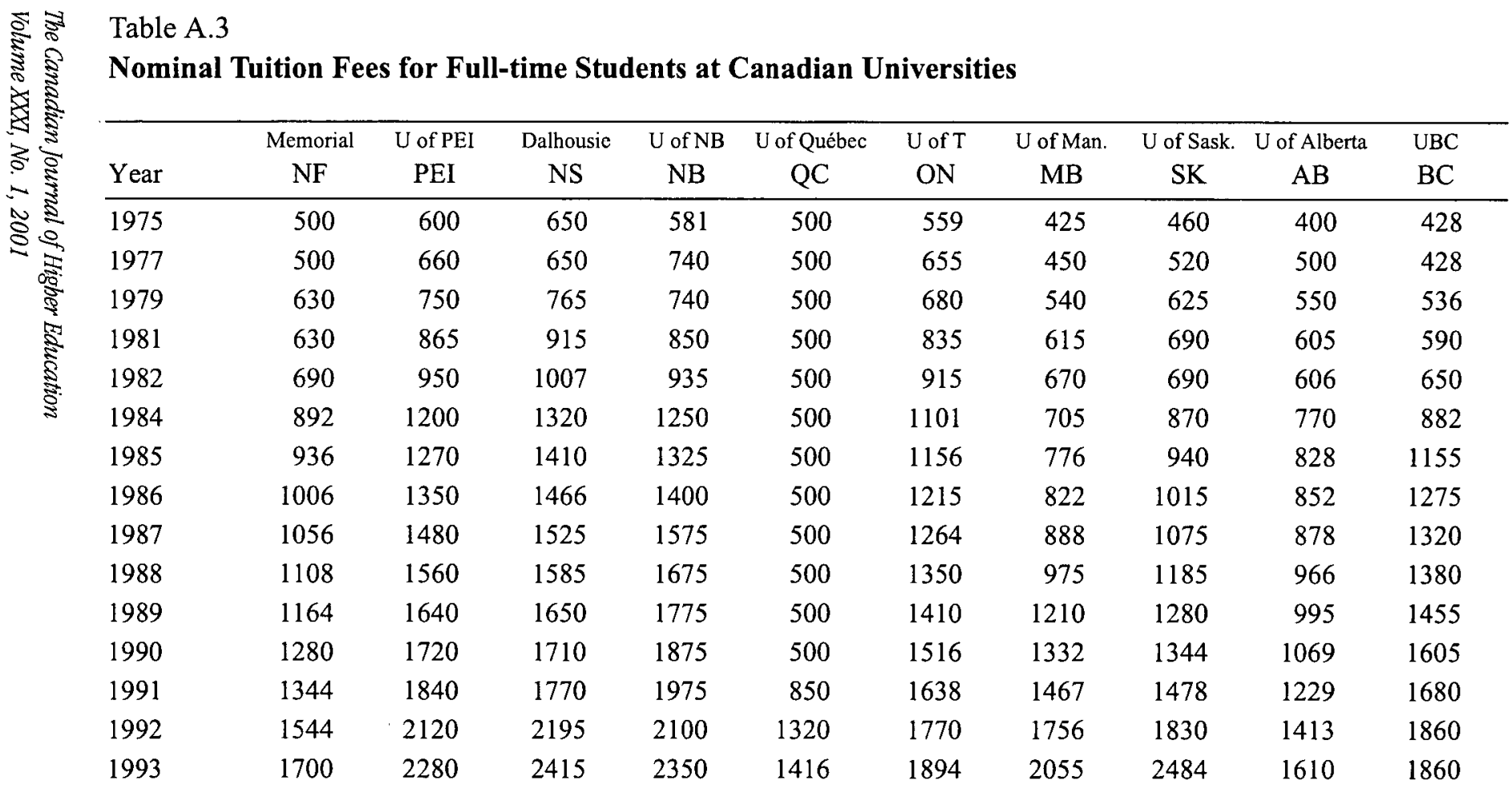

Source: Statistics Canada, Tuition and living accommodation costs at Canadian universities (81-219). University fees are used as a proxy for postsecondary education tuition fees. 